\title{
RESPONSE OF GROUND SUPPORTED CYLINDRICAL TANKS TO HARMONIC LOADING
}

\author{
Asha Joseph ${ }^{1}$ and Glory Joseph ${ }^{2}$ \\ ${ }^{1}$ Research Scholar, Cochin University of Science and Technology, Kerala \\ ${ }^{2}$ Associate Professor, Cochin University of Science and Technology, Kerala
}

\begin{abstract}
Liquid storage tanks such as water distribution systems, petroleum plants etc constitute an important component of life line systems. Reducing earthquake effects on Liquid Storage tanks, in order to minimize the environmental and economic impact of these effects, have always been an important engineering concern. In this paper, the dynamic behaviour of cylindrical ground supported concrete water tanks is investigated. Analyses are carried out on tank models with different aspect ratios using finite element software ANSYS. The natural frequencies and modal responses are obtained for impulsive and sloshing modes. An increase of aspect ratio from 0.2 to 0.6 causes to increase impulsive natural frequency 3 times and sloshing natural frequency 2 times for tank filled with water. The response of the tank to the harmonic loading is also discussed. Deformation and stress response parameters for various frequencies of harmonic loading were also investigated. The harmonic response of tanks with different fill conditions were studied for tanks with aspect ratio 0.25 and 0.35 . For tank of aspect ratio 0.25 , the responses variations are not significant as in the case of tank with aspect ratio 0.35 .
\end{abstract}

\section{KEYWORDS}

Liquid storage tanks, Free response analysis, Harmonic analysis, Aspect ratio

\section{INTRODUCTION}

Liquid storage tanks, used for storage of different types of materials such as water for drinking and fire fighting, petroleum, chemicals, liquid natural gas and nuclear spent fuel are important components of human societies and industrial facilities. Satisfactory performance of these tanks during earthquake is crucial for modern facilities. Poor performance of ground supported and elevated liquid storage tanks has been observed in major past earthquakes (1). Earthquake damages to tanks may result in undesirable consequences such as shortage of water, spillage of dangerous chemical and liquefied gases and resultant contaminations and fire. Damaged tanks containing petroleum or other hazardous chemicals could cause irreparable environmental pollution (2). For liquid containing tanks a wide variety of failure mechanisms are possible, depending upon the configuration of tank geometry, possible fluid-structure-soil interaction, and a lot of other factors such as the tank material, type of support structure, etc. On the other hand, characteristics of earthquakes also significantly influence the response of liquid storage tanks. Typical damages to tanks during past earthquakes include: buckling of tank walls due to excessive development of compressive stresses, rupture of tank shell at the location of joints with pipes, collapse of supporting tower of elevated tanks , cracks in the ground supported reinforced concrete tanks, etc. $(3,4)$

The primary interest of this study is to evaluate the natural frequency both impulsive and sloshing modes of vibrations and dynamic response to harmonic loading of cylindrical ground supported concrete tanks. Parametric study is carried out on circular tanks with different aspect ratio, using finite element software ANSYS. This study adopts Lagrangian approach for incorporating liquid structure interaction. 


\section{FLUID STRUCTURE INTERACTION}

Early studies on seismic response of liquid storage considered the tank as rigid body and attention was focused only on dynamic response of tank's liquid content. After some earthquakes such as Niigata,1964; Alaska,1964: and Parkfield,1966; which caused severe damage to liquid storage tanks, it was observed that rigid tank concept for modeling of tank could not be adopted for modeling tanks. Interaction between the tank wall and the liquid has to be taken into account in the seismic analysis of liquid storage tanks since the tanks itself deform under earthquake loads (5).

Seismic analysis of liquid storage tank is complicated due to the complicated fluid structure interaction of the system. Seismic energy is transferred from the ground to the fluid through the motion of the tank. A portion of the liquid accelerate with the tank where as the remaining liquid is assumed to slosh. Sloshing occurs in the upper part of the liquid, which does not displace laterally with the tank wall (6). Hydrodynamic response can be separated into impulsive motion, in which liquid is assumed to be rigidly attached to tank and moves in unison with tank wall and convective motion, characterized by long period oscillations and involves vertical displacement of fluid's free surface(7). The ground supported tanks can be idealized as shown in fig.1. The impulsive mass of liquid ' $\mathrm{m}_{\mathrm{i}}$ ' is rigidly attached to tank wall at height ' $\mathrm{h}_{\mathrm{i}}$ ' and convective mass ' $\mathrm{m}_{\mathrm{c}}$ ' is attached to the tank wall at height ' $h_{c}$ ' by a spring of stiffness $K_{c}(8)$. The division of the hydrodynamic pressure into the impulsive and convective parts has proved to be of great value in the analysis of tanks excited laterally.

The impulsive pressures are associated with the forces of inertia produced by impulsive movements of the walls of the container, and the pressure developed is directly proportional to the acceleration of the container walls. The convective pressure is produced by oscillations of the fluid and is the consequences of the impulsive pressure (9). Because of large differences in natural periods of impulsive and sloshing responses, these two actions can be considered uncoupled (10).

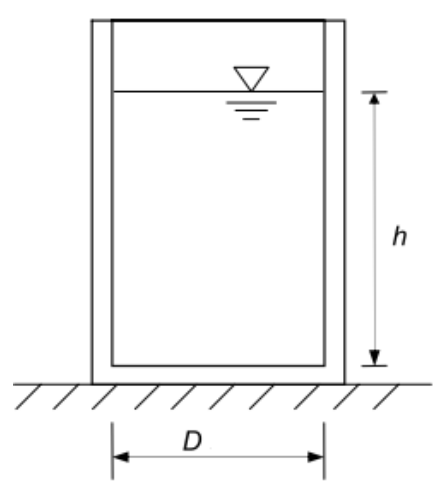

(a) Tank

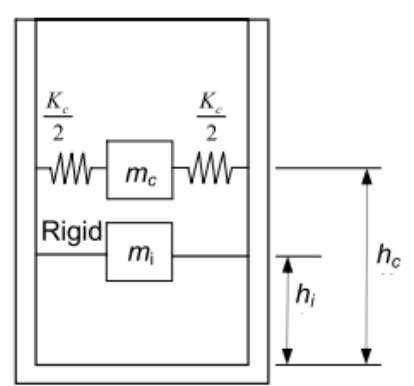

(b) Spring mass model

Fig 1. Spring mass model for ground supported circular tank

\section{Finite Element Formulation Of TANK AND WATER}

Cylindrical ground supported water tank of height $12 \mathrm{~m}$ and $0.5 \mathrm{~m}$ thick side walls and base slab is considered for the study. To study the effect of aspect ratio (the ratio of height of the tank wall, $\mathrm{H}$, to the outer diameter of the tank $\mathrm{D}$ ) on the dynamic behavior, tanks with aspect ratio 0.20 , $0.25,0.3,0.35,0.4,0.45,0.5,0.55$ and 0.6 were modelled. The properties of concrete tank and water considered in the study are given in Table 1. The main assumptions of the present model 
are (i) the tank wall is rigid and (ii) the tank is resting on rock, so that soil-structure interaction is not included in the analysis. The fluid structure interface is identified and fluid nodes are coupled at all interfaces with containing structure. The displacement degrees of freedom at the base of the tank are arrested in all directions.

Table 1. Properties of Concrete and water

\begin{tabular}{|c|c|c|c|c|}
\hline \multicolumn{3}{|c|}{ Concrete } & \multicolumn{2}{c|}{ Water } \\
\hline Density & $\begin{array}{c}\text { Modulus of } \\
\text { Elasticity }\end{array}$ & Poisson's ratio & Density & $\begin{array}{c}\text { Bulk } \\
\text { Modulus }\end{array}$ \\
\hline $2500 \mathrm{~kg} / \mathrm{m}^{3}$ & $27.39 \mathrm{GPa}$ & 0.16 & $1000 \mathrm{~kg} / \mathrm{m}^{3}$ & $2.2 \mathrm{GPa}$ \\
\hline
\end{tabular}

The tank was modeled with SOLID186 element which is a higher order 20-node element. The fluid within the tank was modeled with the FLUID30 (Acoustic-3D30element). The coupling of acoustic pressure and structural motion at the interface has been taken into account in the governing equation for acoustics. The FLUID30 element has eight corner nodes with four degrees of freedom per node: translations in the nodal $\mathrm{x}, \mathrm{y}$ and $\mathrm{z}$ directions and pressure. The translations are applicable only at nodes that are on the interface. The acceleration effects, such as in sloshing of water may be included. The free surface boundary condition can be used to simulate the sloshing problems. The element has the capability to include damping of sound absorbing material at the interface as well as damping within the fluid.

For fluid structure interaction problems the acoustic and the structural matrices are coupled using equation (i), where $M_{s}$ represent mass of tank and $M_{f}$ mass of fluid, $C_{s}$ and $C_{f}$ damping coefficient of tank and water, $K_{s}$ and $K_{f}$ stiffness coefficient of tank and water, $R$ is the coupling matrix that represents the effective surface area associated with each node on the fluid-structure interface (FSI), $F_{s}$ and $F_{f}$ structural and fluid load quantities produced at fluid structure interface in terms of unknown nodal degrees of freedom $u$ and $p$.

$\left\{-\omega^{2}\left[\begin{array}{cc}M_{s} & 0 \\ \rho_{0} R^{T} & M_{f}\end{array}\right]+j \omega\left[\begin{array}{cc}C_{s} & 0 \\ 0 & C_{f}\end{array}\right]+\left[\begin{array}{cc}K_{s} & -R \\ 0 & K_{f}\end{array}\right]\right\}\left\{\begin{array}{l}u \\ p\end{array}\right\}=\left\{\begin{array}{l}f_{s} \\ f_{F}\end{array}\right\}$

The finite element models with boundary conditions generated in ANSYS for a circular tank of aspect ratio 0.35 is shown in fig. 2 .

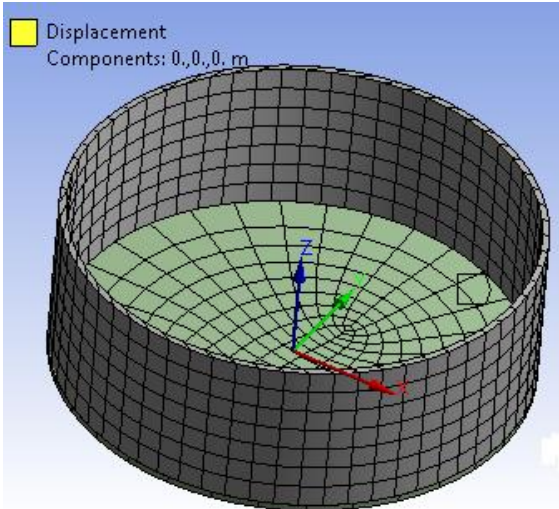

(a) Tank with boundary conditions

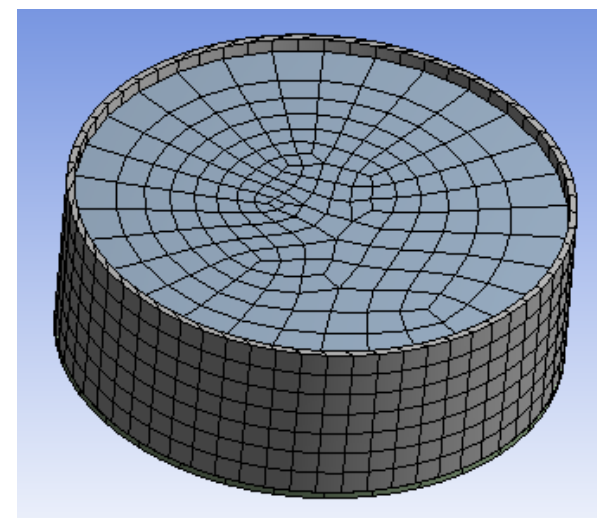

(b) Tank filled with water

Fig 2. Finite element model of tank and water 


\section{FreE Vibration ANALYSIS}

Prior to performing harmonic analysis, free vibration analysis is carried out on the tank models filled with water for $11 \mathrm{~m}$ height. The tank is assumed to have the fixed boundary condition at the base. The natural frequencies and modal responses are obtained using FE methods for impulsive and sloshing modes with the highest participation factors among all modes of vibration. The results of modal analysis are presented in Table 2.

Table 2. Natural frequency of circular tanks $(\mathrm{H}=12 \mathrm{~m})$ for various aspect ratios

\begin{tabular}{|c|c|c|c|c|c|c|}
\hline \multirow{2}{*}{$\begin{array}{c}\text { Aspect } \\
\text { ratio } \\
(\mathrm{H} / \mathrm{D})\end{array}$} & \multicolumn{3}{|c|}{$\begin{array}{c}\text { Impulsive frequency of } \\
\text { tank filled with water } \\
\end{array}$} & \multicolumn{3}{|c|}{$\begin{array}{c}\text { Sloshing Frequency of } \\
\text { tank filled with water } \\
(\mathrm{Hz})\end{array}$} \\
\cline { 2 - 8 } & Mode1 & Mode2 & Mode3 & Mode1 & Mode2 & Mode3 \\
\hline 0.60 & 44.71 & 75.24 & 106.09 & 0.213 & 0.283 & 0.342 \\
\hline 0.55 & 40.50 & 67.81 & 94.93 & 0.201 & 0.268 & 0.321 \\
\hline 0.50 & 37.03 & 61.92 & 86.36 & 0.191 & 0.255 & 0.305 \\
\hline 0.45 & 34.09 & 56.91 & 79.13 & 0.181 & 0.244 & 0.291 \\
\hline 0.40 & 29.49 & 49.15 & 68.25 & 0.165 & 0.225 & 0.269 \\
\hline 0.35 & 25.8 & 43.29 & 59.9 & 0.149 & 0.209 & 0.251 \\
\hline 0.30 & 22.06 & 36.70 & 50.74 & 0.133 & 0.187 & 0.229 \\
\hline 0.25 & 18.37 & 30.54 & 42.20 & 0.115 & 0.168 & 0.206 \\
\hline 0.20 & 14.68 & 24.38 & 33.61 & 0.09 & 0.143 & 0.168 \\
\hline
\end{tabular}

The variation in natural frequency with respect to aspect ratio is shown in Fig 3. It can be seen that both impulsive and sloshing frequency increases with aspect ratio of tank. For tank filled with water, impulsive natural frequency increases for 3 times and sloshing frequency for 2 times as the aspect ratio increases from 0.2 to 0.6 .
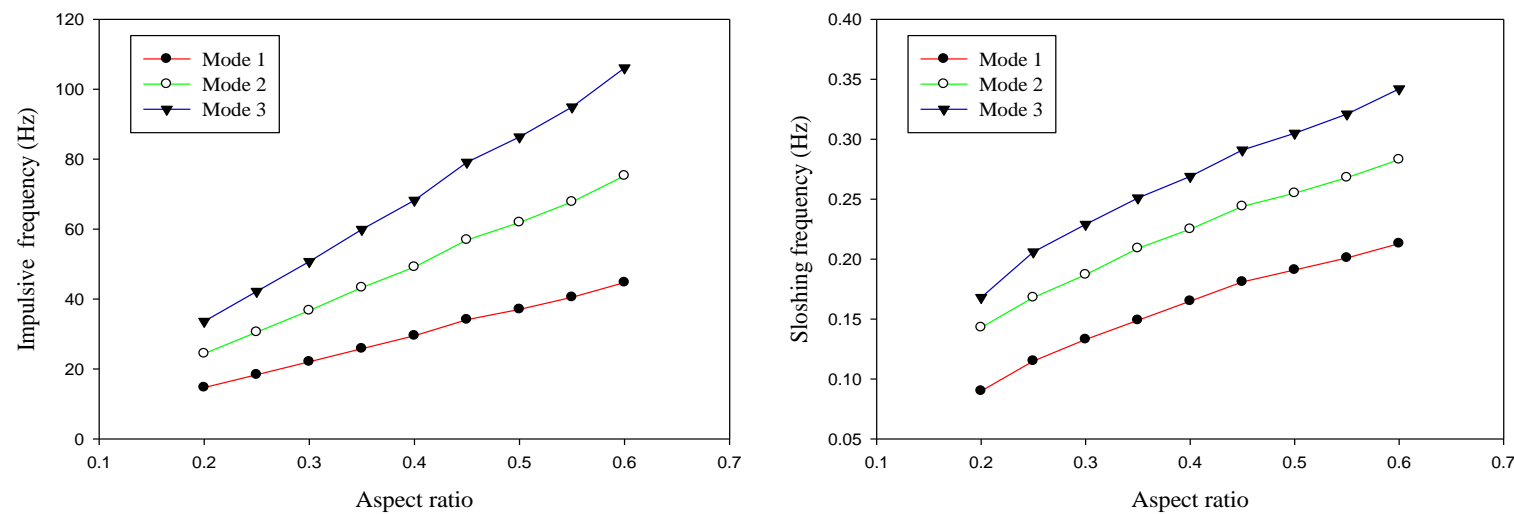

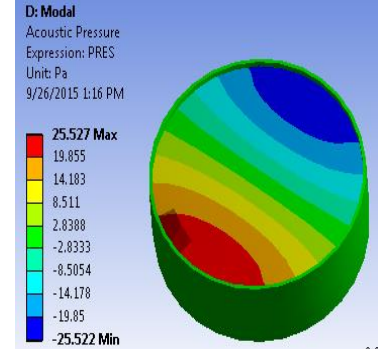

(a) mode 1

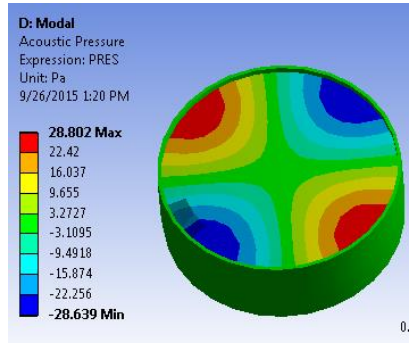

(b) mode 2

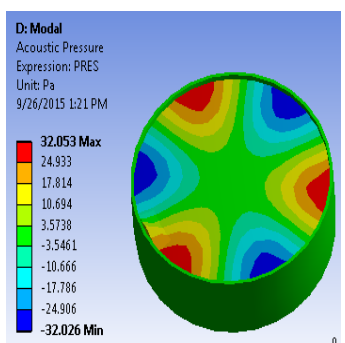

(c) mode 3

Fig 4 Impulsive modes of vibration of the tank $(\mathrm{H} / \mathrm{D}=0.35)$ 


\section{HARMONiC ANALYSIS OF WATER TANK}

Any sustained cyclic load will produce a sustained cyclic response in a structural system. Harmonic response analysis gives us the ability to predict the sustained dynamic behavior of structures, thus enabling us to verify whether or not our designs will successfully overcome resonance, fatigue, and other harmful effects of forced vibrations.

In the present study, harmonic analyses were carried out on tanks with different aspect ratios having water for $11 \mathrm{~m}$ height. Harmonic acceleration of $0.1 \mathrm{~g}$ is applied in the $\mathrm{X}$ direction. Responses of the structure were noted for a frequency range of 0-100 Hz. Maximum hoop stress, normal stress and radial stress developed in the tank having aspect ratio 0.35 at frequency $9 \mathrm{~Hz}$ is shown in Fig 5. For higher frequencies the responses has indicated that the stresses are above the permissible stress limit for concrete. Normal stress is found to be maximum at the bottom of tank wall for all frequencies as expected. Location of point of maximum hoop stress on tank wall varies with respect to frequency and aspect ratio. Fig 6 shows maximum response of von Mises stress and total deformation of the tank body for the tank having aspect ratio 0.35 .

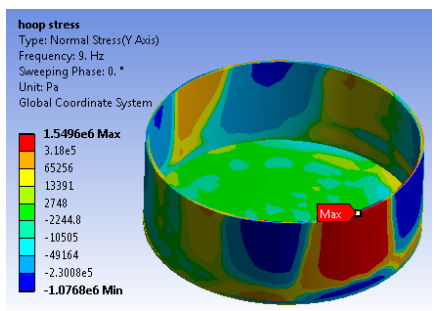

(a)

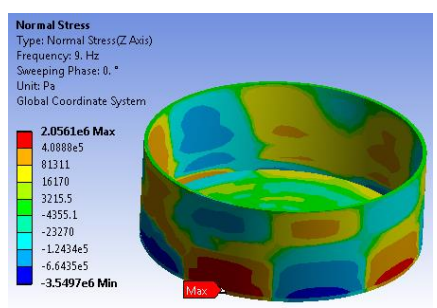

(b)

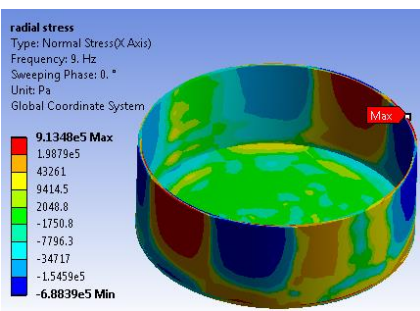

(c )

Fig 5. Stress distribution (a) Hoop stress (b) Normal stress (c ) Radial stress in cylindrical tank (frequency $9 \mathrm{~Hz}, \mathrm{H} / \mathrm{D}=0.35)$

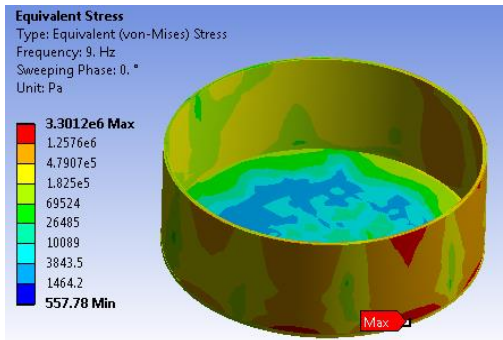

(a)

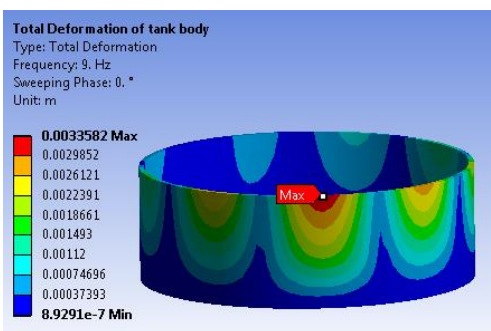

(b)

Fig 6. Responses parameters (a) von Mises stress (b) total deformation of circular tank (frequency $9 \mathrm{~Hz}, \mathrm{H} / \mathrm{D}=0.35$ )

For tanks of various aspect ratios, the response of maximum deformation of top edge of the tank on the inner surface in the direction of harmonic loading with respect to variation in frequency is plotted in Fig 7(a). Hoop stress variation with frequency is also investigated and is shown in Fig 7(b). From the graphs it can be noted that there are large variations in response parameters with frequency of forcing function. 


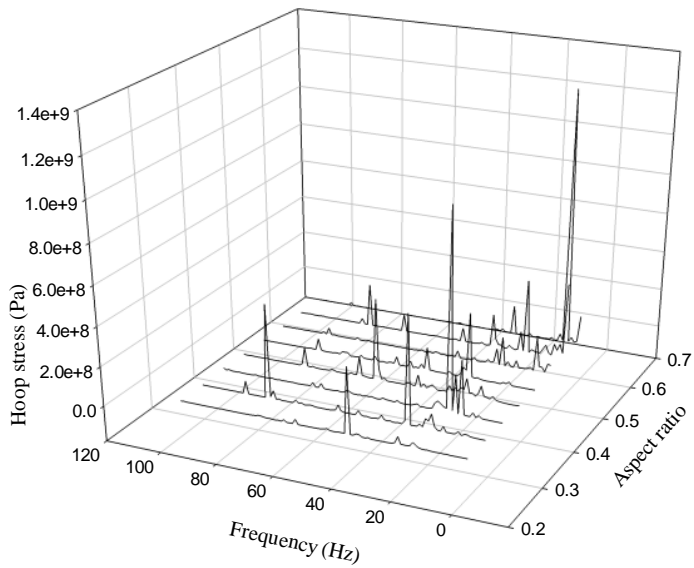

(a)

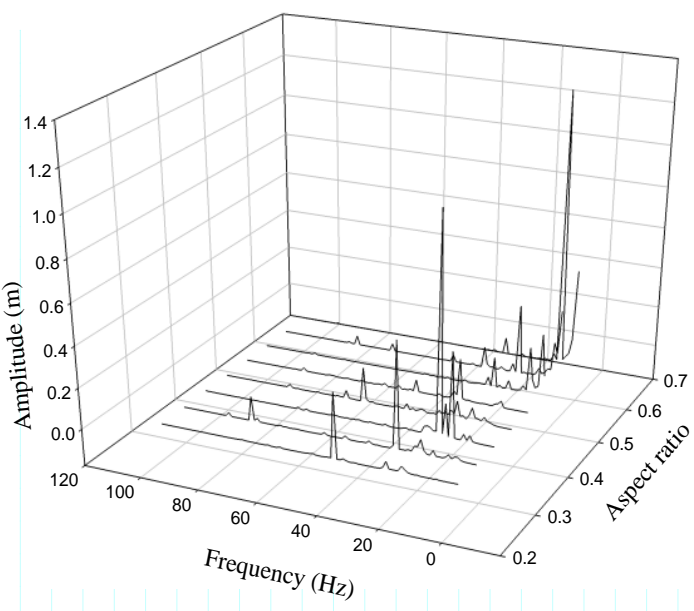

(b)

Fig 7 Frequency response of (a) hoop stress on outer surface of tank (b) deformation of top edge of tank

\section{Influence Of Water Level On Harmonic Response Of Tank}

For tanks having aspect ratio 0.35 and 0.25 , the response parameters were studied for tank full, $2 / 3$ full and 1/3 full conditions. The response displacement of top edge of the tank wall in the direction of loading $(\mathrm{X})$ is studied for frequency range $0-50 \mathrm{~Hz}$ as fundamental frequency of these tanks lies in the range. The response displacements are plotted in Fig 8.

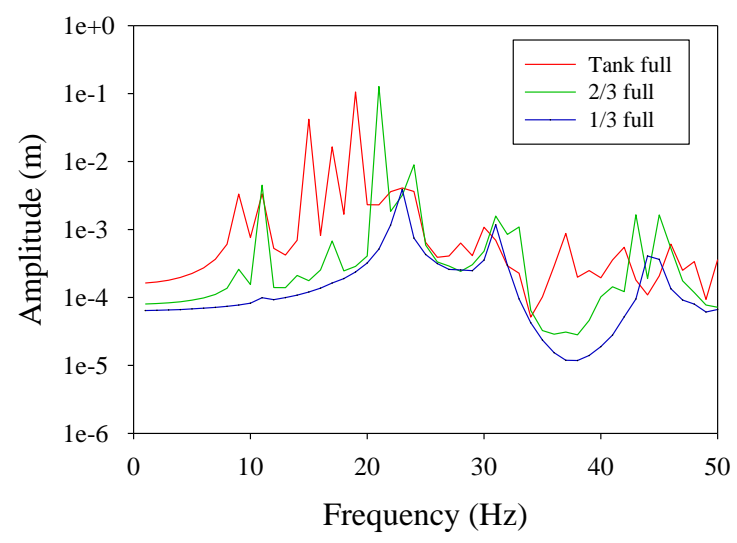

(a)

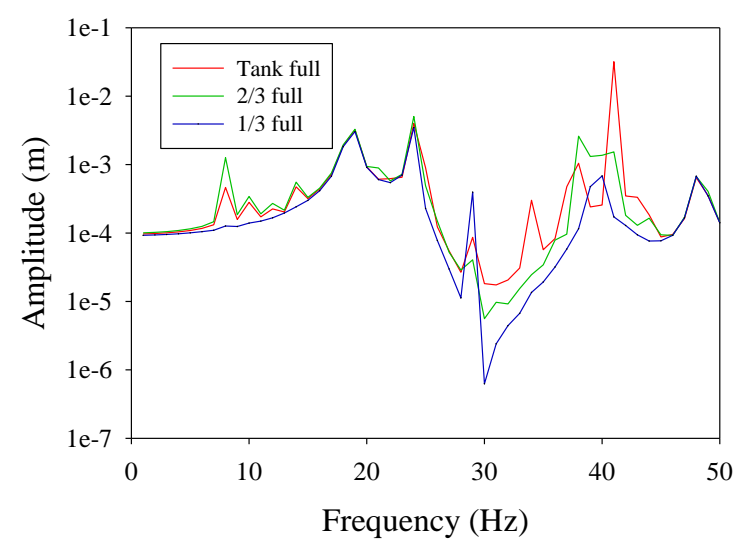

(b)

Fig 8. Displacement of top edge of tank wall (a) aspect ratio 0.35 , (b) aspect ratio 0.25

It can be seen from the graph, for tank having aspect ratio 0.35 , at lower frequencies, the response parameters are maximum for tank full condition, then for $2 / 3$ and $1 / 3$ filled condition as expected. However for tank of aspect ratio 0.25 , the responses variations are not significant as in the case with aspect ratio 0.35.The variation in maximum normal stress and hoop stress on the tank wall with the frequency $(0-10 \mathrm{~Hz})$ is shown in Fig. 9 and Fig.10 for tanks with aspect ratio 0.35 and 0.25 respectively. 

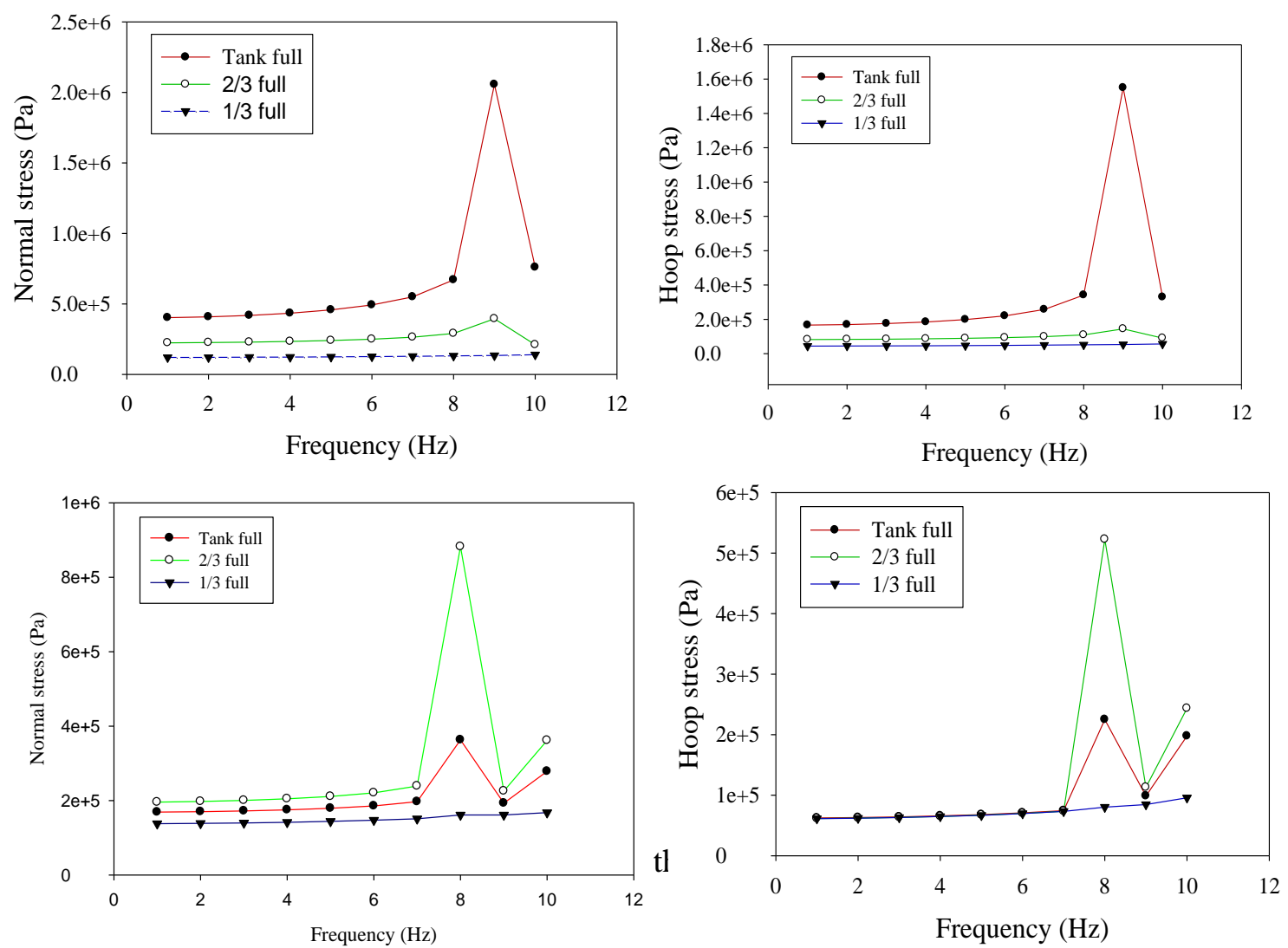

For tank with aspect ratio 0.35 , the maximum normal stress and hoop stress occurs at full tank condition shows exponential increase over the corresponding values at $2 / 3$ and $1 / 3$ filled condition at excitation frequency of $9 \mathrm{~Hz}$. For tank with aspect ratio 0.25 , the maximum normal stress and maximum hoop stress occurs at $2 / 3$ full condition is $142 \%$ and $132 \%$ respectively higher than the corresponding values of full tank condition. The peak values are corresponding to frequency $8 \mathrm{~Hz}$.

\section{CONCLUSIONS}

Conclusions drawn from the present study on circular tanks with different aspect ratio are given below.

1. For tanks of same height and of same material, natural frequency increases with increase in aspect ratio. An increase of aspect ratio from 0.2 to 0.6 causes an increase of 3 times impulsive natural frequency and 2 times sloshing natural frequency of the tank filled with water.

2. The sloshing frequency is much less than that of impulsive frequency and both impulsive and sloshing frequency can be considered as uncoupled.

3. Harmonic analysis indicates that the location of maximum hoop stress on the tank wall varies with aspect ratio as well as the forcing frequency. Also, there is large variation in response parameters with frequency of excitation.

4. For tank with aspect ratio 0.35 , the response parameters in the frequency range $0-10 \mathrm{~Hz}$ is higher for tank full condition and the maximum response occurs at $9 \mathrm{~Hz}$. In the case of tank with aspect ratio 0.25 , the response parameters are maximum for $2 / 3$ full condition and this condition occurs at $8 \mathrm{~Hz}$. 
It can be found that, the dynamic response of water tanks not only depends on the aspect ratio, but tank fill conditions and frequency of excitation also has significant influence.

\section{REFERENCES}

[1] S. Hashemi, M. M. Saadatpour And M. R. Kianoush, "Dynamic Behavior Of Flexible Rectangular Fluid Containers," Thin-Walled Structures, 2013, 66, 23-38.

[2] R. Livaoglu, "Investigation Of Seismic Behavior Of Fluid-Rectangular Tank-Soil/Foundation Systems In Frequency Domain," Soil Dynamics And Earthquake Engineering, 2008, 28, 132-146.

[3] H. Sezen, R. Livaoglu And A. Doganun, "Dynamic Analysis And Seismic Performance Analysis Of Above Ground Liquid Containing Tanks", Engineering Structures, 2008, 30, 794 -803.

[4] O. R. Jaiswal1, S. Kulkarni And P. Pathak, "A Study On Sloshing Frequencies Of Fluid-Tank System," The 14hworld Conference On Earthquake Engineering, Beijing, China, 2008, 12-17.

[5] K. H. Cho And S. Y., "Cho, Seismic Response Of Cylindrical Steel Tanks Considering Fluid Structure Interaction,” Steel Structures, 2007, 7, 147 -152.

[6] A. A. Seleemah And M. El-Sharkawy, "Seismic Response Of Base Isolated Liquid Storage Ground Tanks," Ain Shams Engineering Journal, 2011, 2, 33-42.

[7] M. Moslemi, M.R. Kianoush And W.Pogorzelski, "Seismic Response Of Liquid Filled Elevated Tanks," Engineering Structures, 2011, 33, 2074 - 2084.

[8] Iitk-Gsdma Guidelines For Seismic Design Of Liquid Storage Tank, Indian Institute Of Technology, Kanpu,2005

[9] G. W. Housner, "Dynamic Pressure On Accelerated Fluid Containers," Bulletin Of Seismological Society Of America, 1957, 47, 15-37.

[10] J. C. Virella, L. A. Godoy And L. E. Suraez, "Fundamental Modes Of Tank Liquid Systems Under Horizontal Motions," Engineering Structures, 2006, 28, 1450-1461.

\section{AUTHORS}

Asha Joseph is research scholar in Division of Civil Engineering, School of Engineering, Cochin university of Science and Technology, Kerala. Her research is in the area of dynamic behavio ur of structures. She is a member of Institution of Engineers (India) and life member of Indian Society for Technical Education (ISTE).

Glory Joseph is Associate Professor in Division of Civil Engineering, School of Engineering, Cochin University of Science and Technology, Kerala, India. Her research interests include dynamic behaviour of structures, lightweight concrete and composite structures.
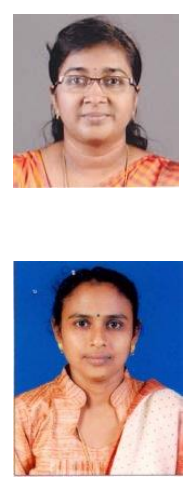